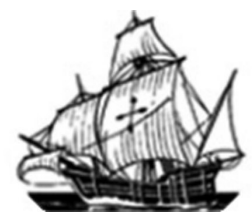

\title{
Vozes negras femininas: reflexões no Centro de Giro Caboclo Boiadeiro
}

\author{
Carla do Espírito Santo Xavier ${ }^{1}$
}

\begin{abstract}
Resumo: o presente texto é resultado de notas de um trabalho de campo. Os relatos trazidos fazem parte de uma pesquisa que teve como objetivo refletir acerca das identidades e trajetórias de mulheres negras do Centro de Giro Caboclo Boiadeiro (Candomblé Angola), em Teodoro Sampaio - Bahia. Neste sentido, uma questão fundamental foi refletir sobre de que modo a experiência religiosa, através de rituais, mitos e arquétipos fundamentam as identidades e trajetórias destas mulheres. A citada pesquisa é de natureza qualitativa com base na Crítica Cultural, seu aporte metodológico, se define pela interpretação e análise de histórias de vida e narrativas memorialísticas de mulheres negras, também construídas através de entrevistas, observação das mulheres dentro e fora do espaço religioso. Assim, observou-se um processo de movência identitária tanto de Mãe Raimunda quanto do Centro de Giro.
\end{abstract}

Palavras-chave: identidade; mulher negra; vozes; iniciação.

Résumé: Cet article est le résultat d'un travail de terrain des notes. Les rapports ont mis le cadre d'une enquête qui visait à réfléchir sur les identités et les trajectoires de centre Giro Boiadeiro Caboclo des femmes noires (Candomblé Angola) à Teodoro Sampaio - Bahia. En ce sens, une question clé était de réfléchir sur la façon dont l'expérience religieuse, à travers des rituels, des mythes et des archétypes qui sous-tendent les identités et les trajectoires de ces femmes. La recherche citée est de nature qualitative basée sur la critique culturelle, son approche méthodologique, définie par l'interprétation et l'analyse des histoires de vie et des récits de femmes noires memorialísticas également construits au moyen d'entrevues, l'observation des femmes à l'intérieur et à l'extérieur de l'espace religieux. Ainsi, il y avait un processus d'identité movência fois Raimunda Mère que le Centre Giro.

Mots-clés: identité; les femmes noires; voix; initiation.

\section{INTRODUÇÃO}

\footnotetext{
${ }^{1}$ Mestranda do programa de Pós-graduação em Crítica Cultural pela Universidade do Estado da Bahia - Campus II -Alagoinhas.

Bolsista da FAPESB - Email: carl-abebe@hotmail.com
} 
Neste texto, me disponho a relatar os primeiros momentos vividos no trabalho de campo sobre o candomblé da Yalorixá Raimunda de Ogum (conhecida como dona Mundinha), em Teodoro Sampaio - BA. As narrativas fazem parte de um projeto de pesquisa que surgiu a partir das aulas no componente curricular Teorias e Críticas da Cultura, do Programa de Pós-Graduação em Crítica Cultural da Universidade do Estado da Bahia Campus II - Alagoinhas, ministrada pelo professor Doutor Arivaldo Lima.

A pesquisa nasceu com o objetivo refletir acerca das identidades e trajetórias de mulheres negras do Centro de Giro Caboclo Boiadeiro (Candomblé Angola), em Teodoro Sampaio - Bahia. Refletir-se-ia sobre de que modo a experiência religiosa, através de rituais, mitos e arquétipos fundamentam as identidades e trajetórias destas mulheres. Para tanto, fizemos uso das histórias de vida e narrativas memorialísticas de mulheres negras desse espaço como metodologia da pesquisa.

A proposta de pesquisa faria parte de um projeto maior, liderado pelo professor Arivaldo Lima. Após alguns esclarecimentos, em orientação, comecei a procurar em Teodoro Sampaio algum terreiro de Candomblé Angola. Nesse processo de busca, as respostas se direcionavam para um só lugar, o terreiro de Dona Mundinha.

Conversei, a priori, com alguns filhos e filhas do terreiro. Procurei saber se, realmente, o terreiro era de Angola. As respostas vinham cheias de incertezas, ou pelo menos o respeito à voz daquela que é a zeladora do terreiro "acho que sim, mas é melhor você perguntar à velha". Em uma oportunidade, encontrei o Ogã do terreiro e fiz a mesma pergunta, obtive a seguinte resposta: "É, é sim. Mas acho melhor você ir lá em cima e conversar com ela".

Percebi, pelas respostas, que existe uma hierarquia que é respeitada pelos adeptos do terreiro. Algo muito comum em comunidades tradicionais, neste caso, o candomblé. A voz respeitada em questão é a voz de uma mulher, Mãe Mundinha.

Na observância do candomblé na Bahia percebemos uma forte representação feminina, principalmente quando nos remetemos aos grandes nomes desse espaço, a saber: Mãe Menininha do Gantois, Mãe Stela de Oxossi, Mãe Raimunda de Ogum entre outras. Essa representatividade é marcada pela presença das mulheres com elevados graus na hierarquia do candomblé. Não obstante, a presença feminina não afugenta os homens. Pelo contrário, atualmente, muitos deles têm assumido o cargo de sacerdotes líderes das casas de candomblé, como babalorixás. Em face de tantas funções, ainda são as mulheres que ocupam cargos exclusivos dentro das hierarquias. 
$\mathrm{Na}$ perspectiva de estudar uma comunidade narrativa tradicional, com foco nas mulheres estruturei a pesquisa apoiada no método da história oral com ênfase na história de vida, bem como na escuta atenta das vozes presentes naquele espaço. A voz é um dos principais instrumentos das pessoas na arte de contar história e trazer à tona as suas memórias. Partindo desse principio, é um meio importantíssimo de preservação da tradição e da memória nas comunidades tradicionais que têm, na oralidade, um modo singular de se comunicar, de produzir cultura e de fazer perpetuar suas histórias.

Quanto às intenções que circundavam a pesquisa, o intuito não era fazer uma etnografia da religião, mas perceber como os saberes advindos do candomblé Angola ativavam um ator social nas mulheres que fazem parte desse tipo de candomblé. Isso posto, era inevitável a minha ida ao terreiro. Porém, antes de ir, muitas pessoas me disseram, "Saiba como chegar, não pergunte muito, escute. No candomblé aprendemos na observação". Em posse dessas dicas e na companhia de um amigo que frequenta o terreiro, lancei-me no campo de pesquisa.

É hora de ir. Surge uma tensão imensa, pois diante de um terreiro de candomblé, o sentimento é de mistério, um segredo iminente e até medo ao adentrar num espaço que tem uma doutrina fechada, pouco se sabe sobre os ritos que fundamentam seus cultos. Provavelmente, mais do que as outras Religiões, o Candomblé é revestido por diversos segredos, muitos desses são conhecidos, apenas, pelas autarquias da religião. As autoridades denominadas: zeladores, pais e mães de santo, mas também como Yalorixás e babalorixás.

Os mistérios que fazem parte da aura do candomblé são compreendidos a partir do processo histórico. Por terem sido discriminados, perseguidos e presos, sobretudo na década de 40 do século XX, os candomblecistas encontraram nos mistérios do culto e nos segredos, a âncora para manter a integridade deles e da própria mantença da religião.

Imbuída dessas informações comecei a jornada em direção ao terreiro. As tentativas foram inúmeras. Uma delas no período da trezena de Santo Antonio. Ao chegar à casa, Márcia, filha de Mundinha, recebeu-me e esclareceu que a mãe não poderia me atender, posto que estava recolhida se concentrando para a matança que haveria no dia seguinte.

Passado o período festivo retornei na companhia de um amigo que frequenta o centro. Ao adentrar na casa, as informações começaram a surgir. Dona Mundinha revela que não tem nenhum problema com as outras religiões, inclusive tem dois filhos evangélicos e não consegue entender porque tanto ela, quanto os adeptos dessa religião são tão discriminados. 
Fomos bem acolhidos e convidados a conversar no barracão (lugar da gira, espaço onde se realiza os ritos). Ao nos ser apresentado, observamos de forma bem clara vários territórios em um mesmo espaço. O quarto das águas onde encontramos a divindades como Oxum, Janaina, Iemanjá, dentre outros. Os elementos presentes neste quarto se remetem as forças das águas, a saber: as cores azul, branco e verde, a fonte artificial.

Ao lado mais um território, o local das consultas. Um elemento marcante nesse espaço é a imagem de Caboclo Boiadeiro. Uma cadeira e um copo d'água ajudam a compor o cenário. Nesse lugar Mãe Raimunda dá conselhos, recomenda banhos e chás, entre outras coisas. A seguir, para ilustrar, uma imagem de Caboclo Boiadeiro retirada da internet:

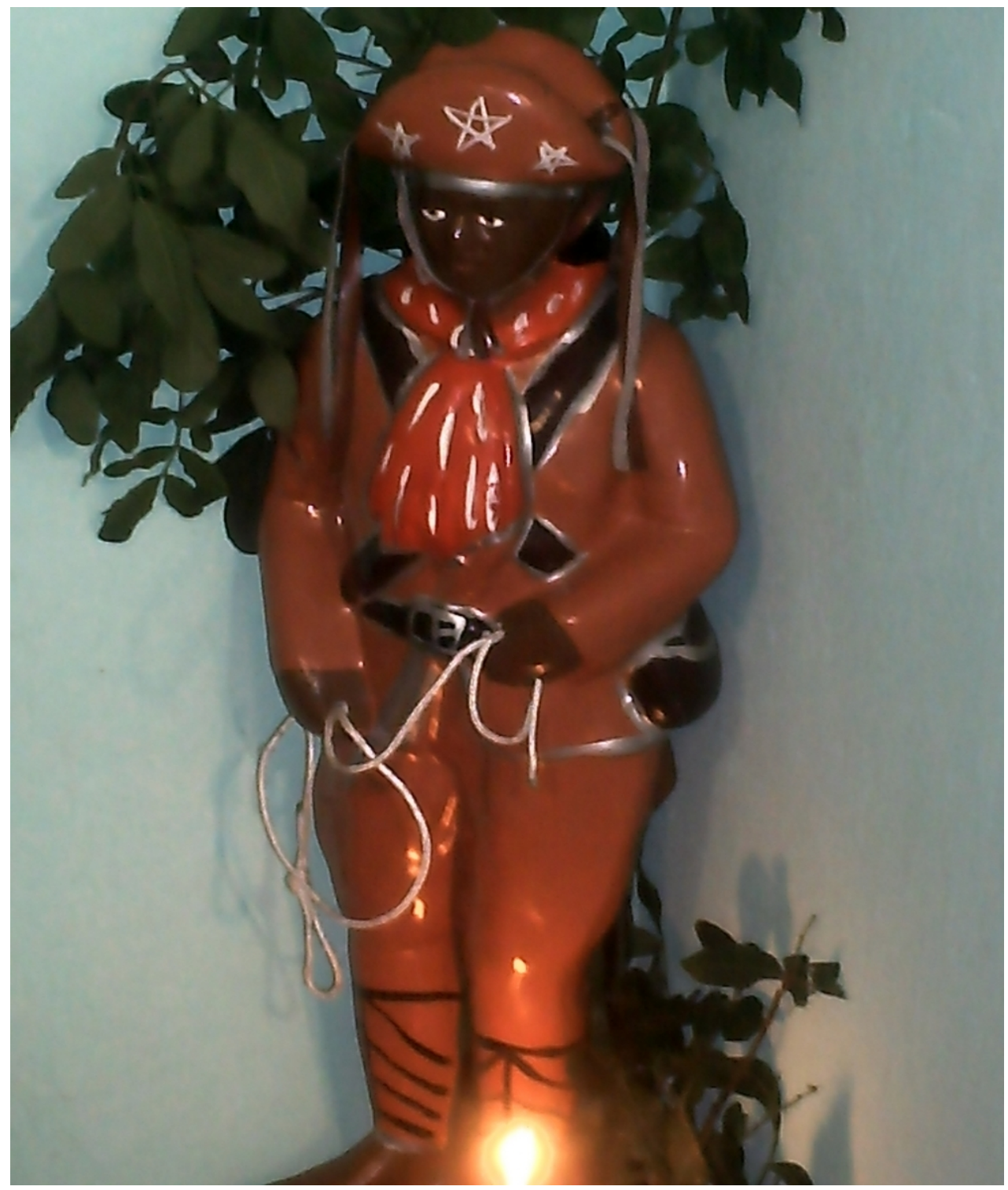

Em mais um quarto encontramos a imagem de Santo Antonio. Ali Mundinha revela "esse aqui não tem nada a ver com ali. Aqui é onde rezo a trezena de Santo Antônio". É intrigante e emblemática essa narrativa. Como se aquele espaço estivesse a parte, não 
estivesse conectado com aquele lugar. Talvez seja leviano fazer essa afirmação, mas sentir assim.

Um confusão se instalou na minha cabeça e se materializava na grande mistura encontrada. A verdade é que o pesquisador vai à campo pensado no puritanismo do objeto pesquisado. Buscava uma identidade fixa, um terreiro de candomblé Angola, não estava preparada para a mistura. Assim, considerarei que a nação Angola não é objeto arqueológico, posto que, por mais que se escavasse não encontraria, nem na África, algo original, intocado, pois como elemento da cultura, ela é dinâmica e é uma produção, passível de modificação.

Essas impressões ebuliam nos meus pensamentos. Não tive a coragem de interromper para questionar: o por quê de tantas misturas? Por que a presença de santos católicos e elementos da Umbada? Porque os termos caboclos e o próprio nome, Centro de Giro? À minha cabeça ecoava a frase não se faz perguntas, aprende-se na observação. Contudo, ficou latente que em algum momento seriam esclarecidos alguns pontos que até então não estavam claros.

Caí na cilada armada por mim mesma. A busca de uma identidade unificada, única. Isso encontra eco nos escritos de GRUZINSKI (p.52) "mas outra cilada espreita o pesquisador: a noção de identidade que atribui a cada criatura ou a cada grupo humano características e aspirações igualmente determinadas".

Retornando a apresentação do espaço. No salão nos foi apresentado Caboclo Boiadeiro, "este é meu pai Boiadeiro, em algumas casas ele é tratado como um egum, um espírito de morto, mas, aqui, na minha casa ele é tratado como um encantado, pois não somos obrigados a ser como todo mundo" e continuou "essa é minha mãe Oyá, guerreira, senhora do fogo e das tempestades" e assim foram apresentados os orixás mais conhecidos Ogum, Oxossi, Iemanjá, Xangó, Obaluaé e Oxum.

Diante dessa premissa, teci o texto a partir de duas questões primordiais. A primeira calca-se na construção da identidade da mulher pela sociedade identificando seu papel em relação ao homem e do processo hierárquico no candomblé. A segunda se estabelece considerando a construção da identidade da iniciação de Dona Mundinha no candomblé e sua relação com o terreiro.

\section{GÊNERO, RAÇA E ENTRELAÇAMENTOS}


O conceito de gênero como constructo social, ou seja, homens e mulheres são resultados da realidade social e não a decorrência da anatomia. A escolha desse conceito me permitiu abandonar a explicação de que a natureza é a grande propulsora das diferenças existentes entre homens e mulheres. $\mathrm{O}$ conceito de gênero adotado nessa discussão encontra eco em Joan Scott :

o gênero é igualmente utilizado para designar as relações sociais entre os sexos. O seu uso rejeita explicitamente as explicações biológicas, como aquelas que encontram um denominador comum para várias formas de subordinação no fato de que as mulheres têm filhos e que os homens têm uma força muscular superior. O gênero se torna, aliás, uma maneira de indicar as "construções sociais": a criação inteiramente social das ideias sobre os papéis próprios aos homens e às mulheres. É uma maneira de se referir às origens exclusivamente sociais das identidades subjetivas dos homens e das mulheres. (ibdem, 1995, P.3).

Historicamente, observa-se que o comportamento dos homens e mulheres, na sociedade, é reflexo de intenso aprendizado sociocultural, no qual cada um tem que agir de acordo com as prescrições sociais de cada gênero. Há uma ordem instituída para a regulação do comportamento humano dizendo que mulheres devem ser de um jeito, e os homens de outro; a mulher ocupa esse lugar e o homem aquele lugar. Na verdade é a construção de um destino linear onde o patriarcalismo favorece ao homem. Conforme Etienne Balibar no seu texto A Forma Nação: História e Ideologia, ao argumentar que:

A história das nações, começando pela nossa própria, sempre nos é apresentada na forma de uma narrativa que atribui a essas entidades a continuidade de um sujeito. A formação da nação aparece-nos, assim, como a consumação de um "projeto" ao longo dos séculos. (ibdem, 1990, p. 1).

A problematização sobre esse aspecto conduz à perspectiva de que a apropriação da nação deve gerar outras narrativas desfazendo a ilusão de destino e sujeitos lineares, situada num processo onde são transmitidos valores invariáveis. Ancorada numa reflexão que vai de encontro à imutabilidade das coisas e dos sujeitos, principalmente na relação de poder entre homens e mulheres.

Desse modo, há um engendramento de produção das desigualdades de oportunidade na nossa sociedade, de condições e de direitos entre homem e mulheres. Diante disso cria-se a hierarquia de gênero ${ }^{2}$ que favorece, em diferentes contextos sociais, o homem.

A partir de tal concepção, a discriminação de gênero coloca a mulher em desvantagem em relação ao homem, em diversas situações sociais. Essas desvantagens ganham força quando o fator de gênero se une às questões de raça, isto é, a mulher negra é muita mais discriminada do que a mulher branca.

\footnotetext{
${ }^{2}$ Pirâmide social econômica construída pelas relações de assimetria de gênero em que existe desigualdades de oportunidades, condições de direito entre homens e mulheres.
} 
Além de lutarem contra a exclusão social, muitas mulheres têm que enfrentar os preconceitos advindos da posição de subordinação que ocupam em relação aos homens no contexto socioeconômico. Quando essa mulher é negra a situação de discriminação se agudiza.

Diante desse contexto, não podemos nos refutar de registrar a importância e a contribuição das mulheres negras presentes no candomblé para questionamento, discussão e transformação do quadro das desigualdades de gênero na sociedade. Pois é inconteste o poder das mulheres nas religiões de matriz africana.

\section{IDENTIDADE COMO PROCESSO DE ACEITAÇÃO/REJEIÇÃO}

A discussão sobre identidade é muito delicada devido a sua imprecisão e consistência. Sua definição se torna mais complexa quando lançamos mão de alguns adjetivos, negro, gênero, etnia, social, juvenil, profissional, religião como afirma Nilma Lino Gomes (2005, p. 40)

Neste texto, optei por abordar a identidade dentro de uma perspectiva cultural, que é construída a partir da dinâmica da visão que temos de nós mesmos, o eu e também de como nos veem, o outro. Por isso, a esta não é algo estático, fruto do isolamento de grupos e sociedade, mas se fundamenta na interação do indivíduo com o meio em que está inserido. Vejamos os argumentos de Gomes :

O cientista social Jacques d'Adesky (2001: 76) destaca que a identidade, para se constituir como realidade, pressupõe uma interação. A ideia que um indivíduo faz de si mesmo, de seu "eu", é intermediada pelo reconhecimento obtido dos outros em decorrência de sua ação. Nenhuma identidade é construída no isolamento. Ao contrário, é negociada durante a vida toda por meio do diálogo, parcialmente exterior, parcialmente interior, com os outros. Tanto a identidade pessoal quanto a identidade socialmente derivada são formadas em diálogo aberto. Estas dependem de maneira vital das relações dialógicas estabelecidas com os outros. Esse é um movimento pelo qual passa todo e qualquer processo identitário e, por isso, diz respeito, também, à construção da identidade negra. (GOMES 2005, p.42)

A identidade é um processo constante de construção e reconstrução, aceitação e rejeição, que se prolonga durante toda vida. Ela se constitui nas particularidades do grupo, evidenciando-se pela história, experiência, cultura, religião dentre outros aspectos, que necessariamente, não são iguais ao modo de ser de outros grupos.

Nesses termos a identidade é entendida como uma metamorfose. No candomblé, contrariamente ao que dizem, a identidade não é fixa, mas sofre modificações, principalmente por motivos aceitação dos sujeitos que compõem esse espaço/território. A seguir 
encontraremos no processo de iniciação de Mãe Raimunda e no registro de seu terreiro, um exemplo dessa mobilidade:

Na narrativa a seguir veremos o processo de iniciação de Mãe Mundinha:

Eu não tinha 7 anos completos, faltava poucos meses para 7 anos quando dei meu primeiro chá (suspensão de pensamento). Com 7 anos eu estava na janela e ouvi a zuada de um cavaleiro descendo a ladeira (fez um som imitando ao do cavaleiro), quando eu sentia que ele chegava perto de mim, eu desmaiava, isso era constantemente. Todo mundo pensava que eu tinha epilepsia. Minha mãe foi a seu Constantino (pai de santo famoso em Teodoro Sampaio nos anos 70 e 80 ), ele descobriu que era aquilo, mas eu não aceitava, mas como a gente não se governa, aos 14 anos meu zelador propôs me recolher, mas não foi possível, porque o guardião não respondia, nem o guardião do santo respondia. O que foi que ele fez? Fez o que deveria ter fazer, como todo mundo já sabe né? Então, eu não fui raspada, só fui borizada.

Dona Raimunda enuncia vários acontecimentos, porém, a principal se destaca pelas marcações da narrativa ao se reportar as suas memórias. Um aspecto comum quando se trata de iniciação na religião de matriz africana, a escolha. Parece-me que há uma imposição, a obrigação.

Centrando-me nesse relato relaciono-o com o processo descrito por Nilma Lino Gomes, a identidade enquanto processo de rejeição/aceitação, isso se revela na afirmação de Mundinha quando enuncia que não aceitava a ideia de entrar no candomblé isso se confirma com a afirmação: mas eu não aceitava, mas como a gente não se governa.

Outro aspecto marcante é a movência no sistema de iniciação. A iniciação de Mãe Raimunda postula uma quebra; "só fui borizada" denota que Mãe Raimunda deu apenas a comida a seu orixá. Dessa forma, o processo de principiar "no santo" não se deu pelo modo tradicional, ficando 21 dias no rancó. Em um dado momento da conversa ela explicita que não pode recolher seus filhos de santo para passar pelo processo de raspar, cortar e catular "como todo mundo sabe, eu não levei navalha".

$\mathrm{Na}$ narrativa a seguir observaremos mais acentuadamente $\mathrm{o}$ processo de aceitação/rejeição da identidade de Dona Mundinha no Candomblé:

Quando foi aos 25 anos eu retomei, mas como eu não queria entrei na lei de crente, levei 10 anos, cabo de 10 anos eu retomei, aí foi o jeito que retornei, não vou contar, é impossível! porque foi muita provação, é uma história muito longa. Mas eu retomei em 89 e em 96 eu registrei a minha casa e aqui estou eu.

Assim, as identidades são imbricadas na semelhança a si próprio e no embate consigo mesmo. Sendo continuamente construídas a partir de repertórios culturais e históricos. É um deslocamento, fragmentação que abala a ideia que temos de nós mesmos, como seres integrados, já que em cada situação reagimos, nos comportamos e nos configuramos de 
maneiras diferentes. Para Stuart Hall (2006), o processo de identificação tornou-se variável e problemático e isso produz um sujeito pós-moderno, sem uma identidade fixa:

A identidade torna-se uma celebração móvel: formada e transformada continuamente em relação às formas pelas quais somos representados ou interpretados nos sistemas culturais que nos rodeiam. É definida historicamente, e não biologicamente. O sujeito assume identidades diferentes em diferentes momentos, identidades que não são unificadas ao redor de um eu coerente. (HALL,2006. pg.13)

O processo de assumir identidades diferentes, deslocando-se a partir do contexto acontece não só com grupos minoritários, já que as sociedades modernas desde o final do século XX vêm se transformando. Essas modificações têm fragmentado os desenhos culturais de classe, gênero, sexualidade, etnia, raça. Isso significa que as coisas estáticas/centradas, ou pensadas dessa forma, começaram a se mover, a descentralizar. Essas mudanças recaem sobre nossas identidades, que até então pensávamos ser unificadas e que começam a fragmentar-se, a deslocar-se.

Relacionando as reflexões de Hall e a iniciação de Mãe Mundinha percebe-se uma movência na identidade, essa instabilidade reverberou na constituição do terreiro e revela os porquês de tantas misturas. Cada território no espaço (barracão) traz á tona uma fase da vida e do processo de construção e desconstrução da identidade de Mãe Mundinha. Fases essas que não foram totalmente reveladas por ela, já que seus relatos eram marcados pelo enunciativo "foi muita provação".

Talvez, a única forma de continuar existindo, enquanto instituição religiosa, fosse o processo assimilação, de transformação continua do seu processo identitário, mas isso não significa ausência de identificação. Mas, um processo histórico de sobrevivência pelos motivos que até aquele momento não eram claros. Isso reafirma o pressuposto indicado por Hall e Gomes respectivamente, a identidade é definida historicamente, é móvel, fragmentada, é construída durante toda vida.

\section{REFERÊNCIAS:}

BACHELARD, G.: A formação do espírito científico. São Paulo: Contraponto, 1996.

GINZBURG, Carlo. Sinais: raízes de um paradigma indiciário. In: Mitos, emblemas, sinais: morfologia e história. São Paulo; Companhia das Letras, 1990. 
GOMES, Nilma Lino. Sem Perder a Raiz: Corpo e cabelo como símbolos da identidade negra. $\quad 2^{\mathrm{a}} \quad$ ed $\quad-\quad$ Belo $\quad$ Horizonte: 2008. . Alguns Termos e Conceitos Presentes no Debate Sobre Relações Raciais no Brasil: Uma Breve Discussão. In. Educação anti-racista. Caminhos abertos pela Lei Federal $n^{0}$ 10.639/03. Secretaria de Educação Continuada, Alfabetização e Diversidade. Brasília: 2005. . Trajetórias escolares, corpo negro e cabelo crespo: reprodução de estereótipos ou ressignificação cultural? In: Revista Brasileira de Educação. Set /Out/Nov/Dez2002.

GRUZINSKI, Serge. O pensamento mestiço. Trad. Rosa Freired'Aguiar. São Paulo: Companhia das Letras, 2001.

HALL, Stuart. A Identidade na Pós-modernidade. Tradução de Tomaz Tadeu da Silva e Guacira Lopes Louro. Editora DP\&A, 1992.

SEGATO, Rita Laura. Santos e Daimones, Brasília: UNB, 1995.

ZUMTHOR, Paul. Precisando. In: Introdução à poesia oral. Belo Horizonte: UFMG, 2010, p. $18-45$. 